\title{
Colonic infusion with Propionibacterium acidipropionici reduces severity of chemically-induced colitis in rats
}

\author{
Catherine MICHEL ${ }^{\mathrm{a} *}$, Nathalie ROLAND ${ }^{\mathrm{b}}$, Gérard LECANNU ${ }^{\mathrm{a}}$, \\ Christophe HERVÉ ${ }^{b}$, Jean-Christophe AVICE ${ }^{c}$, Martine RIVAL ${ }^{\mathrm{a}}$, \\ Christine CHERBUT ${ }^{\mathrm{a}}$
}

\author{
${ }^{a}$ Human Nutrition Research Centre, UFDNH-INRA, BP 71627, 44316 Nantes Cedex 3, France \\ b STANDA-Industrie, 14050 Caen Cedex 4, France \\ c UMR INRA-UCBN, EVA, IBFA, Université de Caen, 14032 Caen Cedex, France
}

\begin{abstract}
Propionibacteria are cheese starters, also studied for their probiotic potential. An interesting feature is the ability of some strains to synthesize nitric oxide (NO) from nitrate reduction. NO production is hypothesized to be the mechanism by which some probiotics improve the mucosal barrier in rats. We therefore investigated the ability of two Propionibacterium acidipropionici strains (TL15 \& TL223), which differ in their in vitro production of NO, to improve colitis in rats. Three groups of rats in which colitis was induced by trinitrobenzene sulfonic acid (TNBS), received intracolonic infusions of $9 \mathrm{~g} \cdot \mathrm{L}^{-1} \mathrm{NaCl}(n=6)$, or $0.9 \times 10^{10} \mathrm{CFU} \cdot \mathrm{d}^{-1}$ of TL15 $(n=7)$, or $1.4 \times$ $10^{10} \mathrm{CFU} \cdot \mathrm{d}^{-1}$ of TL223 $(n=7)$, for 7 days. Following treatment, animal weight, food consumption, inflammatory score and myeloperoxydase (MPO) activity, together with changes in intestinal bacteria and SCFA concentrations, were investigated. As expected, both TL223 and TL15 supplements induced detectable counts of $P$. acidipropionici in colonic contents of rats $(7.67 \pm 0.67$ and $7.43 \pm$ $0.50 \log$ eq. CFU.g ${ }^{-1}$, respectively, as determined by real-time PCR). Food consumption and body weight of rats receiving propionibacteria were overall higher than those of rats with $\mathrm{NaCl}(P=0.007$ and $P=0.004)$. Moreover, both propionibacteria infusions similarly and dramatically reduced the gross score for inflammation $(P=0.004)$ as compared with $\mathrm{NaCl}(0.6 \pm 0.3$ and $0.7 \pm 0.5$ vs. $4.8 \pm$ 1.5). A similar effect was observed for MPO activity $(P=0.056)$, which reached $2.50 \pm 1.37 \mathrm{U} \cdot \mathrm{g}^{-1}$ of mucosal tissue for $\mathrm{NaCl}$ vs. $0.05 \pm 0.02$ and $0.26 \pm 0.18 \mathrm{U} \cdot \mathrm{g}^{-1}$ for TL223 and TL15, respectively. This study shows for the first time the potential benefit of propionibacteria in colonic mucosa healing, but the mechanism involved needs to be elucidated.
\end{abstract}

Propionibacterium / probiotic / colonic ulceration / nitric oxide / real-time PCR

Résumé - L'administration colique de Propionibacterium acidopropionici atténue la sévérité de la colite induite chez le rat. Les bactéries propioniques, utilisées comme levains fromagers, sont également étudiées pour leurs propriétés probiotiques. Une caractéristique intéressante concerne la capacité de certaines souches à synthétiser du monoxyde d'azote $(\mathrm{NO})$ lors de la réduction des nitrates. La production de NO est évoquée comme mécanisme d'action de certains probiotiques capables de restaurer la muqueuse intestinale chez des rats. Nous avons donc déterminé l'impact de deux souches de Propionibacterium acidipropionici (TL15 \& TL223) présentant des capacités de synthèse de NO différentes in vitro, sur des colites induites chez le rat. Trois groupes de rats à colite induite par le trinitrobenzene sulfonic acid (TNBS) ont reçu pendant $7 \mathrm{j}$ des infusions intracoliques de solution

\footnotetext{
* Corresponding author: michel@ nantes.inra.fr
} 
saline $\left(9 \mathrm{~g} \cdot \mathrm{L}^{-1} \mathrm{NaCl}\right)$, ou de suspensions de TL15 $\left(0,9 \times 10^{10} \mathrm{UFC} \cdot \mathrm{j}^{-1}\right)$ ou de TL223 $(1,4 \times$

$\left.10^{10} \mathrm{UFC} \cdot \mathrm{j}^{-1}\right)$. Les effets des traitements sur le poids des animaux, leur consommation alimentaire, le score inflammatoire, l'activité myéloperoxydase (MPO) et sur les concentrations intestinales en bactéries et en acides gras à chaîne courte ont été recherchés. Comme attendu, les infusions de TL223 et de TL15 ont induit des niveaux de population détectables de $P$. acidipropionici dans les contenus coliques des rats (respectivement 7,67 $\pm 0,67$ et 7,43 $\pm 0,50 \mathrm{log}$ éq. UFC $\cdot \mathrm{g}^{-1}$, déterminés par PCR quantitative). La consommation alimentaire et le poids des animaux recevant les propionibactéries étaient globalement supérieurs à ceux des animaux recevant le $\mathrm{NaCl}(P=0,007$ et $P=$ $0,004)$. Le score macroscopique inflammatoire observé en présence de $\mathrm{NaCl}(4,8 \pm 1,5)$ était très nettement $(P=0,004)$ diminué par la supplémentation en propionibactéries, sans différence entre les 2 souches $(0,6 \pm 0,3$ et $0,7 \pm 0,5$ pour TL223 et TL15). Un résultat similaire a été obtenu pour l'activité MPO $(P=0,056)$, qui atteignait $2,50 \pm 1,37 \mathrm{U} \cdot \mathrm{g}^{-1}$ de tissu mucosal pour $\mathrm{NaCl}$ alors qu'elle n'était que de $0,05 \pm 0,02$ et $0,26 \pm 0,18 \mathrm{U} \cdot \mathrm{g}^{-1}$ pour TL223 et TL15, respectivement. Cette étude démontre pour la première fois le bénéfice potentiel des propionibactéries pour la cicatrisation de la muqueuse colique, mais le mécanisme mis en jeu reste à déterminer.

\section{Propionibacterium / probiotique / ulcération colique / oxyde nitrique / PCR quantitative}

\section{INTRODUCTION}

Dairy propionibacteria are largely used as starters in cheese technology. Besides this application, they are also studied for their probiotic properties. Indeed, Propionibacterium freudenreichii is able to stimulate the growth of bifidobacteria in vitro $[15,29]$ and some selected strains partially survive during their transit in the human gut and display bifidogenic activity [5, 12]. Propionibacterium acidipropionici CRL 1198 is able to survive in mice intestine, adhering to the epithelium, and induces positive effects on lipid metabolism, on intestinal flora activity $[35,36,48]$ and on immune response [2, 27, 35].

Moreover, some strains belonging to $P$. freudenreichii and P. acidipropionici species are known to reduce nitrate [7]. Nitrous oxide $\left(\mathrm{N}_{2} \mathrm{O}\right)$ [16] and more recently nitric oxide (NO) are described as final products of nitrate and nitrite reduction. Such NO production has been demonstred in vitro for a particular strain of $P$. acidipropionici [3]. NO synthesis has been proposed as the potential mechanism by which some probiotics could reduce inflammation or improve the barrier function in animal models of colonic dysfunctions $[1,19]$. NO synthesis naturally occurs in the intestine due to both epithelial cells and gut-associated immune cells. In this environment, it participates in the defence mechanisms of the intestinal mucosa against exogenous compounds [37].
Because significantly higher NO concentrations and NO synthase (NOS) activities have been detected in patients suffering from inflammatory bowel diseases (IBD) as compared with healthy subjects [38], NO has first been suggested as being involved in the inflammatory process. This deleterious impact is supported by the biological properties of NO. Indeed, NO can modulate COX-2-dependent production of prostaglandins, promote leucocyte chemotaxis, stimulate production of proinflammatory cytokines and activate lymphocytes. NO is also supposed to favor the production of $\mathrm{ONOO}^{-}$, which is a potent oxidant, through interaction with reactive oxygen species such as $\mathrm{O}_{2}^{*}$ [34].

However, experimental studies aimed at assessing the benefit of inhibiting NO production on mucosal healing are far from being conclusive [18]. The administration of selective (L-NIL and 1400w) or nonselective NOS inhibitors (L-NAME and LNMMA) has been reported to attenuate colonic injury in animals with chemicallyinduced colitis [26]. However, in other studies, these inhibitors were ineffective at attenuating colitis in different animal models [43]. Furthermore, other findings suggest that NO could be of benefit in colitis therapy: L-NAME treatment worsened dextransulfate-induced inflammation in rats [47], L-NMMA increased colonic damage when administered in the first 3 days of colitis development [9], and knock-out mice, 
Table I. List of strains used in the study and growth conditions. Strains of Propionibacterium spp. were obtained from different international collections: TL, the collection of the dairy research laboratory UMR-STLO of INRA (Rennes, France); CIP, Bacterial Collection of Pasteur Institute (Paris, France); DSM, German Collection of Microorganisms and Cell Cultures (Braunschweig, Germany). YEL: Yeast Extract Lactate medium [22]; PYG: Peptone Yeast Glucose medium (DSM culture conditions).

\begin{tabular}{lcc}
\hline Collection name & Species & Culture medium and temperature \\
\hline TL223, TL15, TL2, TL54, TL9 & P. acidipropionici & YEL, $30^{\circ} \mathrm{C}$ \\
CIP $103029^{\mathrm{T}}$ & P. thoenii & YEL, $30^{\circ} \mathrm{C}$ \\
CIP $103028^{\mathrm{T}}$ & P. jensenii & YEL, $30^{\circ} \mathrm{C}$ \\
CIP $103027^{\mathrm{T}}$, TL14, TL147, & P. freudenreichii & YEL, $30^{\circ} \mathrm{C}$ \\
TL162, TL166 & subsp. shermanii & \\
CIP $103026^{\mathrm{T}}$, TL3 & P. freudenreichii & YEL, $30^{\circ} \mathrm{C}$ \\
DSM $13435^{\mathrm{T}}$ & subsp. freudenreichii & \\
CIP $101941^{\mathrm{T}}$ & P. microaerophilum & $\mathrm{PYG}, 37^{\circ} \mathrm{C}$ \\
CIP $53117^{\mathrm{T}}$ & P. propionicus & $\mathrm{PYG}, 37^{\circ} \mathrm{C}$ \\
CIP $103262^{\mathrm{T}}$ & P. acnes & $\mathrm{PYG}, 37^{\circ} \mathrm{C}$ \\
CIP $103261^{\mathrm{T}}$ & P. granulosum & $\mathrm{PYG}, 37^{\circ} \mathrm{C}$ \\
\hline
\end{tabular}

which are deficient in iNOS, not only develop a more severe experimental colitis than wild-type mice, but also exhibit delayed healing of their colonic mucosa [25]. Such a beneficial effect of NO has also been suggested from the increased anti-inflammatory activity of NO-mesalamine, as compared with mesalamine alone [44].

Taking all this into account, we investigated whether propionibacteria could improve the mucosal healing in rats in which colitis was induced by trinitrobenzene sulfonic acid (TNBS) and whether this property was related to their NO synthesis ability. As first steps in this goal, different dairy Propionibacterium strains were screened in vitro with respect to their ability to produce NO from nitrate, and a specific and quantitative method for $P$. acidipropionici enumeration by real-time PCR was developed.

\section{MATERIALS AND METHODS}

\subsection{Bacterial strains}

All the strains of propionibacteria used in this work and their culture conditions are listed in Table I. Cells were stored at $-80{ }^{\circ} \mathrm{C}$ in broth culture containing $15 \%$ glycerol. Prior to use, they were subcultured twice (2\% inoculum) as indicated.

\subsection{Nitrate reduction and analysis of NO production in bacterial cultures}

Propionibacteria were grown on YEL medium for $3 \mathrm{~d}$ at $30^{\circ} \mathrm{C}$. Then, subsequent cultures were carried out for $72 \mathrm{~h}$ on $\mathrm{KNO}_{3}$ containing YEL medium (final concentration $650 \mu \mathrm{mol} \cdot \mathrm{L}^{-1}$ ) under a helium atmosphere. At the end of the incubation, NO production was assessed by isotope ratio mass spectrometry (IRMS) according to [3] and residual nitrates and nitrites were quantified in the cell-free supernatants of cultures using a colorimetric test (Boehringer-Mannheim, Meylan, France). Assays were carried out in duplicate.

\subsection{Preparation of bacterial suspensions for in vivo experiment}

Strains TL223 and TL15 were cultivated in YEL medium supplemented with 
$500 \mu \mathrm{mol} \cdot \mathrm{L}^{-1} \mathrm{KNO}_{3}$ for $3 \mathrm{~d}$ at $30^{\circ} \mathrm{C}$. After centrifugation ( $8000 \mathrm{rpm}, 20 \mathrm{~min}, 4^{\circ} \mathrm{C}$ ), the pellets were washed and suspended in $\mathrm{NaCl}$ $9 \mathrm{~g} \cdot \mathrm{L}^{-1}$ (cell concentration $\times 4$ compared with initial cultures). Suspensions were aliquoted into $30-\mathrm{mL}$ portions and frozen at $-20{ }^{\circ} \mathrm{C}$ before use. From enumeration on YEL agar, counts of propionibacteria before and after freeze were, respectively, $1.4 \times 10^{10}$ and $7.1 \times 10^{9} \mathrm{CFU} \cdot \mathrm{mL}^{-1}$ for TL223 and $7.0 \times 10^{9}$ and $4.3 \times 10^{9} \mathrm{CFU} \cdot \mathrm{mL}^{-1}$ for TL15.

\subsection{Animals and treatments}

Twenty male Wistar rats (Janvier, Le Genest Saint Isles, France), with an initial mean weight of $250 \mathrm{~g}$, were housed individually in suspended cages with wiremesh bottoms and maintained at $23^{\circ} \mathrm{C}$ in an animal room with a 12-h light:dark cycle. Food and water were consumed ad libitum, and food intake and body weight were recorded daily. Individual values obtained from day 1 to day 7 were averaged. The diet contained $\left(\mathrm{g} \cdot \mathrm{kg}^{-1}\right)$ : gelatinized cornstarch (626), soluble casein (204), lard (58.5), a mineral mixture (43.7), cellulose (40), corn oil (18.5), a vitamin mixture (5.6) and DLmethionine (3.7). The composition of the mixtures has been detailed previously [20]. The experiment was in accordance with the recommendations of the local Animal Care and Use Committee of Nantes (France).

The rats were surgically equipped with a chronic catheter $(1.0 \mathrm{~mm}$ i.d., $1.8 \mathrm{~mm}$ o.d., Tygon ${ }^{\circledR}$ Tubing, Fisher Bioblock Scientific, Illkirch, France) fixed in the proximal colon, $1.5 \mathrm{~cm}$ beyond the ceco-colonic junction according to [6]. After $5 \mathrm{~d}$ of postoperative recovery, the animals were submitted to colitis induction with trinitrobenzene sulfonic acid (TNBS, $80 \mathrm{mg} \cdot \mathrm{kg}^{-1}$, dissolved in ethanol $400 \mathrm{~g} \cdot \mathrm{L}^{-1}$ ) as described in [6]. The rats were then randomly assigned to 3 groups. Each group was administered with one of the following treatments: saline $\left(9 \mathrm{~g} \cdot \mathrm{L}^{-1} \mathrm{NaCl}\right), \mathrm{TL} 223$ suspension or TL15 suspension for the next $7 \mathrm{~d}$. The treatments $(1 \mathrm{~mL})$ were administered through the catheter twice daily (08:00 a.m. and 05:00 p.m.). The TL223 and TL15 suspensions thus delivered $1.4 \times 10^{10}$ and $0.9 \times 10^{10} \mathrm{CFU}$ per day, respectively.
Fresh stools were collected from the anus of each animal on the day before TNBS infusion and on day 6 (i.e., 1 day before slaughtering) and immediately processed for bacterial enumeration.

At the end of the treatment, the rats were killed by cervical dislocation, $6 \mathrm{~h}$ after the last administration. The large bowel was dissected free from the fat and mesentery, removed, and opened along the mesenteric border.

An aliquot of caecal content was collected and added to $1 \mathrm{~mL}$ of a $\mathrm{HgCl}_{2} / \mathrm{H}_{3} \mathrm{PO}_{4}$ solution (1 g. $\mathrm{L}^{-1}$ and $50 \mathrm{~g} \cdot \mathrm{L}^{-1}$, respectively), then frozen $\left(-20^{\circ} \mathrm{C}\right)$ before SCFA analysis.

The colonic contents were collected and divided into 2 parts: (1) approx. $0.5 \mathrm{~g}$ was collected into a sterile tube for immediate total anaerobe enumeration, and (2) residual material was frozen $\left(-80{ }^{\circ} \mathrm{C}\right)$ in view of Propionibacterium acidipropionici quantification by real-time PCR. Then, the mucosa was carefully cleaned with cold sterile saline and colonic damage and inflammation were assessed as described below. Two colonic tissue samples $\left(1 \mathrm{~cm}^{2}\right)$ were collected for immediate enumeration of mucosaassociated aerobes and anaerobes and for myeloperoxydase (MPO) activity measurement, respectively. The latter was frozen before analysis $\left(-80^{\circ} \mathrm{C}\right)$.

\subsection{Control of $P$. acidipropionici delivery}

The 16S-23S rDNA intergenic spacer region was used to select primers specific to $P$. acidipropionici species. The primers used (QPACIDI for: 5' GATGGTTCGGTTCAGGCTGTC 3' and QPACIDI rev: 5' CCATAGCCACATTCCACTCAG 3') were newly designed using the Primer Express ${ }^{\circledR}$ software (PE Applied Biosystems, Foster City, CA, USA) and were synthesized by Qiagen Operon Europe (Cologne, Germany). The expected size of the amplified DNA was $69 \mathrm{bp}$. DNA was extracted from 2-day-old pure cultures of different Propionibacterium species (strains TL223, TL15, CIP $103029^{\mathrm{T}}$, CIP $103028^{\mathrm{T}}$, CIP $103027^{\mathrm{T}}$, CIP $103026^{\mathrm{T}}$, DSM $13435^{\mathrm{T}}$, CIP $101941^{\mathrm{T}}$, CIP $53117^{\mathrm{T}}$, CIP $103262^{\mathrm{T}}$ and CIP $103261^{\mathrm{T}}$, Tab. I) and from the colonic 
content of the rats, using the QIAamp tissue kit and QIAmp DNA Stool Mini Kit (Qiagen, Hilden, Germany), respectively, according to the manufacturer's instructions. Real-time PCR was conducted using an Applied Biosystems 7000 instrument (Applied Biosystems, Foster City, CA, USA). Reaction mixtures consisted of a total volume of $25 \mu \mathrm{L}$ containing $12.5 \mu \mathrm{L}$ 2 X SYBR Green Master Mix (Applied Biosystems, Foster City, CA) and 8 pmol of each specific primer. Genomic DNA was added at a level of $10 \mathrm{ng}$ or $50 \mathrm{ng}$ for specificity or calibration studies, respectively. In both cases, the conditions for amplification were 1 cycle at $95{ }^{\circ} \mathrm{C}$ for $10 \mathrm{~min}$, followed by 35 cycles of $15 \mathrm{~s}$ at $95{ }^{\circ} \mathrm{C}$ and $60 \mathrm{~s}$ at $60{ }^{\circ} \mathrm{C}$. The purity of the amplicon was verified by analyzing the melting curve over a range of 60 to $99^{\circ} \mathrm{C}$, with incrementations set at $0.2^{\circ} \mathrm{C} \cdot \mathrm{s}^{-1}$. Assays were carried out in triplicate for each DNA sample. To quantify $P$. acidipropionici, a standard curve was constructed and used to interpolate the number of copies present in the rat colonic samples. For this, $100 \mu \mathrm{L}$ of ten-fold successive dilutions of the bacteria were added to $200 \mathrm{mg}$ of the colonic content of the rats without $P$. acidipropionici flora, and thoroughly mixed before DNA extraction.

\subsection{Assessment of colonic damage and inflammation}

Gross colonic damage was scored by an independent observer, unaware of the treatments, according to the scale described by [30]. Each colon was assigned a score ranging from 0 (normal) to 15 (severe damage) indicative of adhesions, ulcerations, gross inflammation of the colonic wall and diarrhea.

The activity of myeloperoxidase (MPO), a specific enzyme marker of polymorphonuclear neutrophil primary granules, was measured using the method of [17] as modified by [6]. Activity was expressed in units per milligram of tissue.

\subsection{Analysis of luminal and mucosa-associated floras}

All samples were added ( $5 \mathrm{~mL}$ for mucosal samples and $9 \mathrm{~mL}$ for stools and for intra- colonic contents) to sterile and anoxic peptone water $\left(7.5 \mathrm{~g} \cdot \mathrm{L}^{-1}\right.$, Oxoid, Dardilly, France) containing cysteine $\left(0.5 \mathrm{~g} \cdot \mathrm{L}^{-1}\right.$, Sigma, St-Quentin-Fallavier, France) immediately after collection. Mucosal sample suspensions were homogenized under $\mathrm{N}_{2}$ flux using an ethanol-sterilized Polytron for $5 \mathrm{~min}$. Fecal and colonic samples were homogenized by vortex for $3 \mathrm{~min}$. All samples were serially diluted ten-fold in the same diluant. $100 \mu \mathrm{L}$ of the appropriate dilutions were inoculated on duplicate plates using unselective media for the enumeration of total anaerobes (Wilkins-Chalgren agar, Oxoid, Dardilly, France) and total aerobes (Nutrient agar, Oxoid, Dardilly, France). Plates were incubated at $37^{\circ} \mathrm{C}$ in anaerobic $\left(\mathrm{H}_{2}: \mathrm{CO}_{2}: \mathrm{N}_{2}-5: 10: 85\right)$ or aerobic conditions, as appropriate, for $72 \mathrm{~h}$. Single colonies were then counted and the results were expressed as $\log \mathrm{CFU} \cdot \mathrm{g}^{-1}$ (wet weight) or $\log \mathrm{CFU} \cdot \mathrm{cm}^{-2}$, as appropriate.

\subsection{SCFA analysis}

SCFA were quantified by gas chromatography [14] on supernatants of thawed samples of cecal contents centrifuged at $8000 \mathrm{~g}$ for $10 \mathrm{~min}$. 4-methyl valeric acid was used as an internal standard. Concentrations were expressed as $\mathrm{mmol} \cdot \mathrm{L}^{-1}$.

\subsection{Statistical analysis}

Statistical analysis was performed using the Statview 5.0 package (SAS institute, Berkeley, CA, USA). Data are expressed as means \pm sem. One-way ANOVA was used to assess the effects of treatments. When a significant effect was observed $(P<0.10)$, individual means were compared by Fisher's Protected Least Significant Difference test. The paired Student's t-test was used to compare the total anaerobe counts enumerated in stools before and after treatment.

\section{RESULTS}

\subsection{In vitro NO production and strain selection}

NO production by the different propionibacteria cultivated in the presence of $\mathrm{KNO}_{3}$ was strain-dependent (Figs. 1a, 1b). 

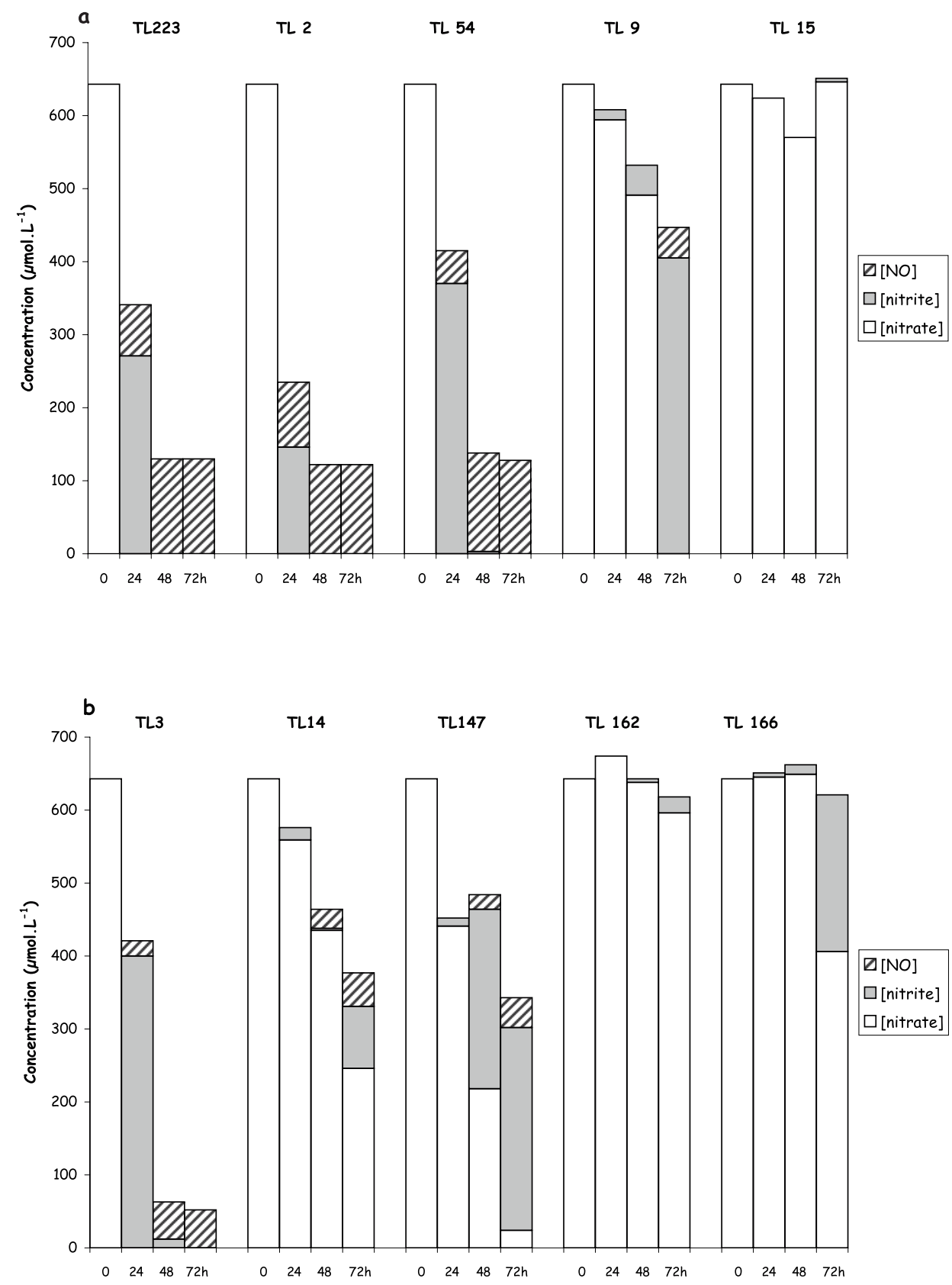

Figure 1. Concentration of nitrate and nitrite in cell-free supernatant of bacterial cultures at 0,24 , 48 and $72 \mathrm{~h}$ of incubation at $30{ }^{\circ} \mathrm{C}$ in YEL medium containing $650 \mu \mathrm{mol} \cdot \mathrm{L}^{-1}$ nitrate, and concentration of NO accumulated in the tubes of culture (expressed as $\mu \mathrm{mol} \cdot \mathrm{L}^{-1}$ of culture) for strains of P. acidipropionici (a) and P. freudenreichii (b). 
The greatest accumulation of NO occurred after $48 \mathrm{~h}$ with strains of $P$. acidipropionici rapidly reducing nitrate then nitrite (TL223, TL2, TL54) and, to a lesser extent, with one strain of $P$. freudenreichii (TL3). Some strains were unable to use nitrate (TL15 and TL162) or reduced it to nitrite very slowly (TL166). In this case, no accumulation of NO was observed. The other strains (TL14, TL147 and TL9) slowly reduced nitrate and nitrite but accumulated significant amounts of $\mathrm{NO}$ after $72 \mathrm{~h}$.

In view of these results, TL223, which produced high amounts of NO, and TL15, which was unable to convert nitrate into NO, were selected for the in vivo experiment.

\subsection{In vivo experiment}

\subsubsection{Control of P. acidipropionici delivery}

Using genomic DNA from different propionibacteria species and the newly designed primer set, PCR amplification was only obtained for P. acidipropionici. This illustrates the specificity of the method developed towards this particular species among propionibacteria. The equation of the calibration curve was $\mathrm{Ct}=-3.37 \log$ (eq. $\mathrm{CFU})+$ 38.34 , with the coefficient of correlation $\left(\mathrm{r}^{2}\right)$ being 0.997 . The PCR efficiency was thus calculated as $97.6 \%$ and the detection threshold was $10^{5}$ eq. CFU.g ${ }^{-1}$ of content.

When this method was applied to the colonic contents of all experimental animals, no signal was obtained in the control group, indicating that the level of $P$. acidipropionici was lower than $10^{5}$ eq. CFU.g ${ }^{-1}$. Conversely, high and similar numbers of $P$. acidipropionici were detected in the colonic contents of rats receiving TL223 and TL15 (7.67 \pm 0.67 and $7.43 \pm 0.50$ CFU. $\mathrm{g}^{-1}$, respectively, $P=0.773$ ).

\subsubsection{Effects of treatments on rats' status and inflammation severity}

Before colitis induction (day 0), all animals exhibited similar daily food intakes $\left(20.8 \pm 1.3 \mathrm{~g} \cdot \mathrm{d}^{-1}, P=0.50\right)$. However, fol- lowing colitis induction (day 1 to day 7 ), the rats receiving saline consumed significantly lower amounts of food $(17.6 \pm 1.1 \mathrm{~g}$ on average on the whole follow-up duration) than those receiving TL223 (23.8 \pm $1.1 \mathrm{~g}, P=0.004)$ or TL15 $(23.3 \pm 1.5 \mathrm{~g}$, $P=0.006)$, which did not differ from each other $(P=0.79)$. Similarly, although comparable body weights were observed for all rats before TNBS treatment (day 0: $287.8 \pm 2.1 \mathrm{~g}$, $P=0.18$ ), the mean body weight of rats receiving saline $(280.3 \pm 4.9 \mathrm{~g})$ was significantly lower than that of rats receiving TL223 $(295.5 \pm 5.5 \mathrm{~g}, P=0.03)$ or TL15 $(292.4 \pm 2.6 \mathrm{~g}, P=0.08)$ following colitis induction (day 1 to day 7). Again, there was no statistical difference $(P=0.63)$ between the two $P$. acidipropionici strains.

Both TL223 and TL15 infusions considerably reduced inflammation compared with $\mathrm{NaCl}$ after only $7 \mathrm{~d}$ of treatment. Indeed, the colonic mucosa of rats receiving $\mathrm{NaCl}$ were severely inflamed at this stage, as indicated by their high macroscopic damage score $(4.8 \pm 1.5)$ and by the elevated MPO activity of their mucosa $\left(2.50 \pm 1.37 \mathrm{U} \cdot \mathrm{g}^{-1}\right.$, Fig. 2$)$. The beneficial impact of TL223 and TL15 infusions was illustrated by the significantly lower values observed for both the macroscopic score $(0.6 \pm 0.3, P=0.003$ for TL223 and $0.7 \pm$ $0.5, P=0.003$ for TL15) and MPO activity $(0.05 \pm 0.02, P=0.029$ for TL223 and $0.26 \pm$ $0.18, P=0.043$ for TL15), while no difference was detected between the two strains ( $P=0.83$ and $P=0.90$ for the macroscopic score and MPO activity, respectively).

\subsubsection{Effects of treatments on intestinal flora and SCFA concentrations}

Neither the total anaerobe counts in the colonic contents nor the total anaerobe and total aerobe counts associated with the colonic mucosa were affected by TL223 or TL15 infusions (Tab. II). Before colitis induction, all animals exhibited similar total anaerobe counts in their stools $(P=0.90$, Fig. 3). However, on the 6th day after colitis induction, the rats receiving saline exhibited significantly lower total fecal anaerobe counts than those receiving TL223 

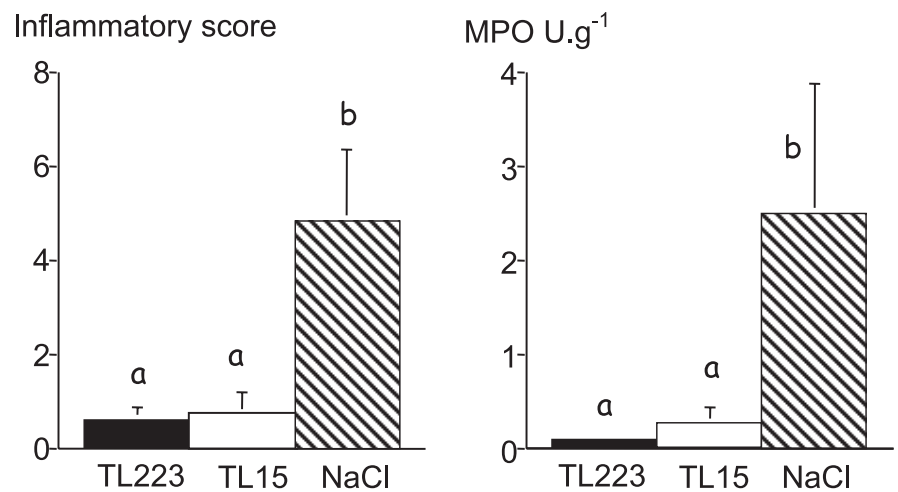

Figure 2. Macroscopic damage scores and myeloperoxidase (MPO) activity in the colonic mucosa of rats with TNBS-induced colitis after intracolonic treatment with $\mathrm{NaCl}, P$. acidipropionici strain TL15 or $P$. acidipropionici strain TL223. Values are means \pm sem. Bars with a different letter differ significantly $(P<0.1)$.

Table II. Intracolonic and mucosa-associated bacterial counts from rats with TNBS-induced colitis, after intracolonic treatment with P. acidipropionici strain TL223, P. acidipropionici strain TL15 or $\mathrm{NaCl}$. Values are means \pm sem.

\begin{tabular}{lcccc}
\hline & TL223 & TL15 & $\mathrm{NaCl}$ & $P$ value \\
\hline $\begin{array}{l}\text { Total anaerobes in colonic } \\
\text { content }\left(\log \mathrm{CFU} \cdot \mathrm{g}^{-1}\right)\end{array}$ & $8.98 \pm 0.46$ & $9.74 \pm 0.28$ & $9.21 \pm 0.20$ & 0.285 \\
$\begin{array}{l}\text { Total anaerobes on mucosa } \\
\left(\log \mathrm{CFU} \cdot \mathrm{cm}^{-2}\right)\end{array}$ & $7.41 \pm 0.33$ & $6.97 \pm 0.20$ & $6.96 \pm 0.42$ & 0.522 \\
$\begin{array}{l}\text { Total aerobes on mucosa } \\
\left(\log \mathrm{CFU} \cdot \mathrm{cm}^{-2}\right)\end{array}$ & $5.74 \pm 0.58$ & $6.19 \pm 0.44$ & $6.15 \pm 0.62$ & 0.810 \\
\hline
\end{tabular}

$\left(9.13 \pm 0.24\right.$ versus $9.80 \pm 0.10 \log$ CFU.g ${ }^{-1}$, $P=0.017)$ while those receiving TL15 showed an intermediate value $(9.52 \pm 0.17)$. Interestingly, t-test comparison on paired data between these two days showed that the decrease in total fecal anaerobe numbers which occurred with $\mathrm{NaCl}$ was not observed when TL223 and TL15 were infused (Fig. 3).

Intracolonic $\mathrm{pH}$ was not affected by treatments (Tab. III). Conversely, total SCFA concentration was significantly lower in animals infused with TL223 and TL15 as compared with controls, with no difference $(P=0.84)$ between the two P. acidipropionici strains (Tab. III). Similarly, lower concentrations of propionate were observed for animals receiving the bacterial suspensions.

\section{DISCUSSION}

This study was carried out in order to assess the ability of some propionibacteria to relieve TNBS-induced colitis in rats and to evaluate whether this beneficial effect could be related to the ability of the strain to produce NO from nitrate.

In this respect, we first determined the in vitro denitrifying ability of different strains of $P$. acidipropionici and $P$. freudenreichii. Our results indicated that nitrate-reducing propionibacteria were able to produce high and steady amounts of $\mathrm{NO}$ and that this property appeared more pronounced in $P$. acidipropionici species, although it was strain-dependent. In NO-producing cultures, this compound accounted for up to 
Table III. $\mathrm{pH}$ values and short-chain fatty acid concentrations in cecal contents of rats with TNBSinduced colitis, after intracolonic treatment with $P$. acidipropionici strain TL223, $P$. acidipropionici strain TL15 or NaCl. Values are means \pm sem. Within a same raw, values with a different letter differ significantly $(P<0.1)$.

\begin{tabular}{lcccc}
\hline & TL223 & TL15 & NaCl & $P$ value \\
\hline$n$ & 7 & 7 & 6 & \\
Cecal $\mathrm{pH}$ & $6.1 \pm 0.1$ & $6.1 \pm 0.1$ & $6.0 \pm 0.1$ & 0.615 \\
Total SCFA $\mu \mathrm{mol} \cdot \mathrm{g}^{-1}$ & $125.3 \pm 7.6 \mathrm{a}$ & $123.6 \pm 3.7 \mathrm{a}$ & $143.8 \pm 6.2 \mathrm{~b}$ & 0.065 \\
Acetate $\mu \mathrm{mol} \cdot \mathrm{g}^{-1}$ & $87.7 \pm 8.6$ & $80.2 \pm 7.3$ & $90.7 \pm 11.1$ & 0.700 \\
Propionate $\mu \mathrm{mol} \cdot \mathrm{g}^{-1}$ & $14.6 \pm 0.9 \mathrm{a}$ & $19.3 \pm 0.9 \mathrm{~b}$ & $22.1 \pm 0.8 \mathrm{c}$ & $<0.0001$ \\
${\text { Butyrate } \mu \mathrm{mol} \cdot \mathrm{g}^{-1}}$ & $20.6 \pm 5.2$ & $21.7 \pm 5.0$ & $28.7 \pm 8.5$ & 0.630 \\
Minor $^{\dagger} \mathrm{SCFA} \mu \mathrm{mol} \cdot \mathrm{g}^{-1}$ & $2.4 \pm 0.2$ & $2.3 \pm 0.4$ & $2.3 \pm 0.4$ & 0.978 \\
\hline
\end{tabular}

$\dagger$ Sum of isobutyrate, isovalerate and valerate.

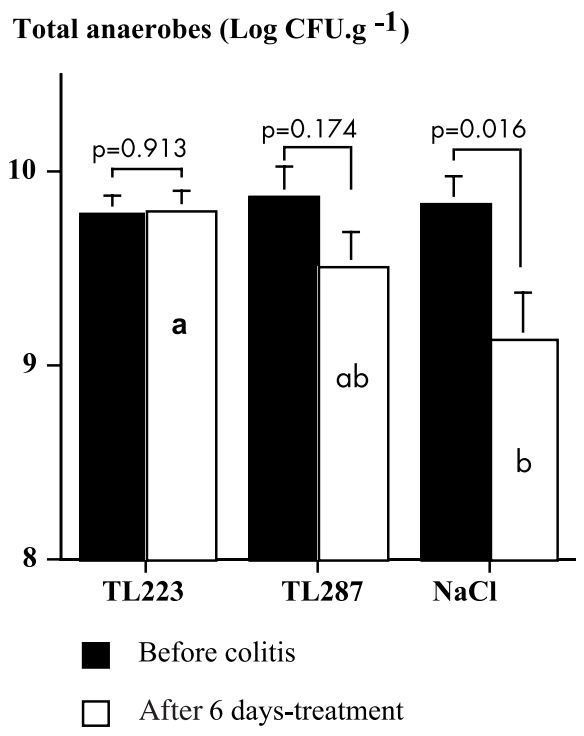

Figure 3. Total anaerobe counts in feces of rats with TNBS-induced colitis before and after intracolonic treatment with $\mathrm{NaCl}, P$. acidipropionici strain TL15 or $P$. acidipropionici strain TL223 for $6 \mathrm{~d}$. Values are means \pm sem. Bars from day 6 with a different letter differ significantly $(P<0.1)$.

$20 \%$ of the initial pool of nitrate. The apparent loss of $80 \%$ of the initial nitrate was probably due to nitrous oxide production, which could not be quantified in our experimental conditions, since such $\mathrm{N}_{2} \mathrm{O}$ accumulation has been reported by [16] for both
P. acidipropionici and P. freudenreichii strains.

Production of bacterial NO has been extensively described in established environmental denitrifiers such as Pseudomonas and Paracoccus [49] but it is very unusual for bacteria which are encountered in the intestine. Indeed, the commensal intestinal flora can efficiently reduce nitrate and nitrite but this phenomenon occurs mainly via a dissimilatory reaction where ammoniac is the final product of nitrite reduction [33]. One exception is some enteric bacteria, which can produce small amounts of NO from nitrite reduction [13]. As far as food or probiotic bacteria are concerned, the ability to produce NO from nitrate has only been reported for Lactobacillus farciminis [45] and Lactobacillus fermentum [46].

Anyhow, the aim of this NO-synthesis screening was to select the strains which would be assessed in vivo with respect to their healing ability against induced colitis. We therefore chose the TL223 and TL15 strains because they were typified in our in vitro conditions as "NO-positive" and "NOnegative" strains, respectively, and because they belong to the same species ( $P$. acidipropionici) which will minimize differences in their phenotypic characteristics.

A specific and quantitative method for $P$. acidipropionici enumeration was thus required to control the comparability of $P$. acidipropionici delivery in both animal groups infused with the two bacterial 
strains. By targeting the $16 \mathrm{~S}-23 \mathrm{~S}$ rDNA intergenic spacer region, we developed in this work a molecular approach which allowed the specific quantification of $P$. acidipropionici species in a digestive environment. Both the PCR efficiency and linearity were satisfactory. The detection limit obtained in this work $\left(10^{5} \mathrm{CFU} \cdot \mathrm{g}^{-1}\right)$ is intermediate between that described in human stools for the detection of Lactobacillus helveticus $\left(10^{4} \mathrm{CFU} \cdot \mathrm{g}^{-1}\right)$ and various species of Bifidobacterium $\left(10^{6} \mathrm{CFU} \cdot \mathrm{g}^{-1}\right)$ $[24,40]$. When applied to the colonic contents of experimental animals, this method revealed that $P$. acidipropionici supplementation was strictly comparable in both animal groups infused with the bacteria.

In this context, our in vivo data demonstrated the beneficial impact of the two investigated strains of $P$. acidipropionici towards colonic inflammation in the TNBSinduced colitis rat model. Indeed, intracolonic infusions of TL223 and TL15 suspensions in $\mathrm{NaCl}$ restored both the daily food intake and the animal body weight as compared with $\mathrm{NaCl}$ alone. Weight loss and the slight anorexia observed with saline are typical of colonic inflammations, as previously observed in animals with chemically-induced colitis $[6,23]$ or in patients suffering from inflammatory bowel diseases [39]. Administration of both bacterial strains efficiently reduced these symptoms immediately after colitis induction, suggesting that $P$. acidipropionici may exert beneficial effects on the onset of the inflammation. Moreover, this administration significantly reduced the severity of the intestinal inflammation induced by TNBS, producing less damage to the mucosa and decreasing MPO activity in the colonic wall. These observations confirm previous data indicating that some probiotics may protect against experimental intestinal inflammation [6, 19, 21, 23, 31], against inflammatory bowel diseases [41] or against dysfunction of the intestinal barrier [1]. Some of these studies have hypothesized that this benefit originates from $\mathrm{NO}$ synthesis by probiotics $[1,19]$. This suggestion cannot be supported by our findings since the two bacterial suspensions infused were similarly efficient at reducing colonic inflammation while differing in their in vitro ability to convert nitrate into NO. However, the contribution of bacterial NO synthesis cannot be definitively excluded, since in vivo NO production was not quantified in this study. In vivo conditions may have affected bacterial NO production by propionibacteria as compared with in vitro ones, and have stimulated NO production from TL15. Alternatively, considering that the commensal intestinal bacteria intensively reduce nitrate to ammonia [33], the in vivo conditions may also have inhibited NO production by TL223 due to competition for nitrate.

Numerous other mechanisms have been proposed in order to explain the benefit of probiotics towards colonic inflammation [41]. Among them is the interaction between the probiotic and the colonic flora, resulting either in modulation of colonic mucosal adherent flora or of the luminal flora [21]. Such a possibility needs to be considered for propionibacteria since some of these bacteria have been reported to be highly adherent to epithelial cells both in vitro and in vivo $[10,32,48]$ while another study has demonstrated that propionibacteria administration to humans increases the fecal numbers of Bifidobacterium sp. [5]. In our study, neither the luminal nor the mucosaassociated bacteria numbers were affected by propionibacteria supplementation. However, this does not exclude some modulation of the bacterial composition which has not been characterized here. The only detected effect of $P$. acidipropionici infusions on intestinal flora was a restoration of the initial bacterial density in feces after $6 \mathrm{~d}$ of treatment. Taking into account that stools from animals receiving $\mathrm{NaCl}$ alone were more watery than those from animals receiving the propionibacteria suspensions (data not shown), the change in fecal bacterial numbers induced by TL 15 and TL 223 probably results from a lower dilution of the bacteria in the feces. It would therefore be subsequent rather than initiating in the process of mucosa healing.

Other potential mechanisms of probiotics are: (i) antagonism to pathogenic bacteria through acidification of the ceco-colonic lumen; (ii) production of SCFA which beneficially affect numerous key functions of 
the colonic epithelium [4, 11], and (iii) interaction with the immune response [41]. From our observations, neither of the two former mechanisms seems involved. Indeed, administration of propionibacteria suspensions did not affect the luminal acidity of the hindgut and SCFA concentration was not increased but decreased when TL15 and TL223 were infused. Although apparently contradictory to the well-known propionate production by Propionibacterium sp. [7], such a decrease in intracolonic SCFA concentrations has already been observed in TNBS-induced colitic rats which were treated with a mix of lactic acid bacteria as compared with those treated with $\mathrm{NaCl}$ alone [6]. In this case, the decrease in SCFA concentrations was observed only after $14 \mathrm{~d}$ of administration, i.e. at the stage where the benefit of the treatment was maximal. Considering this, one could hypothesize that the lowering impact of propionibacteria on the intracolonic concentration of SCFA would be subsequent to their healing effect on the mucosa, through restoration of its uptake potential. This scenario is supported by the fact that inflamed colonic mucosa exhibit a decreased SCFA absorption ability together with a decreased SCFA metabolism as compared with a healthy one, but these decreases are limited to the acute phases of inflammation and are rapidly compensated with healing [8, 28].

Whether or not modulation of the immune response is involved in the beneficial impact of TL15 and TL223 could not be answered in this study since no immunological parameters were followed up. However, this possibility needs to be considered since some $P$. acidipropionici strains increase phagocytose and $\operatorname{IgA}$ production in both in vitro and in vivo conditions $[2,27,36]$, two properties which are supposed to be involved in the protective effect of probiotics against intestinal inflammation $[41,42]$.

\section{CONCLUSION}

Finally, our results demonstrated for the first time a beneficial impact of $P$. acidipropionici on colonic inflammation in the TNBS-induced colitis rat model, with this benefit appearing to be independent from the in vitro ability of the strains to produce nitric oxide from nitrate. Thus, the involved mechanisms of $P$. acidipropionici need to be further investigated.

Aknowledgements: The authors are grateful to J. Coutret, A. David and F. Doulay for technical assistance.

\section{REFERENCES}

[1] Adawi D., Molin G., Jeppsson B., Inhibition of nitric oxide production and the effects of arginine and Lactobacillus administration in an acute liver injury model, Ann. Surg. 228 (1998) 748-755.

[2] Alvarez S., Medici M., Vintini E., Oliver G., de Ruiz Holgado A.P., Perdigon G., Effect of the oral administration of Propionibacterium $\operatorname{IgA}$ levels and on the prevention of enteric infection in mice, Microbiol. Alim. Nutr. 14 (1996) 237-243.

[3] Avice J.C., Ourry A., Lainé P., Roland N., Louahlia S., Roussel E., Brookes S., Boucaud J., A rapid and reliable method for $\mathrm{NO}$ quantification and ${ }^{15} \mathrm{NO} /{ }^{14} \mathrm{NO}$ determination using isotope ratio mass sprectrometry: an application for the detection of NO synthesis in propionibacteria, Rapid Commun. Mass Spectrom. 13 (1999) 1197-1200.

[4] Blottière H.M., Buecher B., Galmiche J.P., Cherbut C., Molecular analysis of the effect of short-chain fatty acids on intestinal cell proliferation, Proc. Nutr. Soc. 62 (2003) 101-106.

[5] Bouglé D., Roland N., Lebeurrier F., Arhan P., Effect of propionibacteria supplementation on fecal bifidobacteria and segmental colonic transit time in healthy human subjects, Scand. J. Gastroenterol. 34 (1999) 144-148.

[6] Cherbut C., Michel C., Lecannu G., The prebiotic characteristics of fructooligosaccharides are necessary for reduction of TNBS-induced colitis in rats, J. Nutr. 133 (2003) 21-27.

[7] Cummins C.S., Johnson J.L., Genus I., Propionibacterium Orla-Jensen 1909, 337 AL, in: Sneath P.H.A., Mair N.S., Sharpe M.E. (Eds.), Bergey's Manual of Systematic Bacteriology, Vol. 2, Williams \& Wilkins, Baltimore, USA, 1986, pp. 1346-1353.

[8] Den Hond E., Hiele M., Evenepoel P., Peeters M., Ghoos Y., Rutgeerts P., In vivo 
butyrate metabolism and colonic permeability in extensive ulcerative colitis, Gastroenterol. 115 (1998) 584-590.

[9] Hosoi T., Goto H., Arisawa T., Niwa Y., Okada N., Ohmiya N., Hayakawa T., Role of nitric oxide synthase inhibitor in experimental colitis induced by 2,4,6-trinitrobenzene sulphonic acid in rats, Clin. Exp. Pharmacol. Physiol. 28 (2001) 9-12.

[10] Huang Y., Adams M.C., An in vitro model for investigating intestinal adhesion of potential dairy propionibacteria probiotic strains using cell line C2BBe1, Lett. Appl. Microbiol. 36 (2003) 213-216.

[11] Jan G., Belzacq A.S., Haouzi D., Rouault A., Metivier D., Kroemer G., Brenner C., Propionibacteria induce apoptosis of colorectal carcinoma cells via short-chain fatty acids acting on mitochondria, Cell Death Differ. 9 (2002) 179-188.

[12] Jan G., Leverrier P., Proudy I., Roland N., Survival and beneficial effects of propionibacteria in the human gut: in vivo and in vitro investigations, Lait 82 (2002) 131-144.

[13] Ji X.B., Hollocher T.C., Reduction of nitrite to nitric oxide by enteric bacteria, Biochem. Biophys. Res. Commun. 157 (1988) 106-108.

[14] Jouany J.P., Volatile fatty acid and alcohol determination in digestive contents, silage juices, bacterial cultures and anaerobic fermentor contents, Sci. Aliments 2 (1982) 131-144.

[15] Kaneko T., Mori H., Iwata M., Meguro S., Growth stimulator for bifidobacteria produced by Propionibacterium freudenreichii and several intestinal bacteria, J. Dairy Sci. 77 (1994) 393-404.

[16] Kaspar H.F., Nitrite reduction to nitrous oxide by propionibacteria: detoxication mechanism, Arch. Microbiol. 133 (1982) $126-130$

[17] Krawisz J.B., Sharon P., Stenson W.E. Quantitative assay for acute intestinal inflammation based on myeloperoxidase activity, Gastroenterol. 87 (1984) 1344-1350.

[18] Kubes P., McCafferty D.M., Nitric oxide and intestinal inflammation, Amer. J. Med. 109 (2000) 150-158.

[19] Lamine F., Fioramonti J., Bueno L., Nepveu F., Cauquil E., Lobysheva I., Eutamène H., Théodorou V., Nitric oxide released by Lactobacillus farciminis improves TNBSinduced colitis in rats, Scand. J. Gastroenterol. 39 (2004) 37-45

[20] Le Blay G.M., Michel C.D., Blottière H.M., Cherbut C.J., Raw potato starch and shortchain fructo-oligosaccharides affect the composition and metabolic activity of rat intestinal microbiota differently depending on the caecocolonic segment involved, $\mathrm{J}$. Appl. Microbiol. 94 (2003) 312-320.

[21] Madsen K.L., Doyle J.S., Jewell L.D., Tavernini M.M., Fedorak R.N., Lactobacillus species prevents colitis in interleukin 10 gene-deficient mice, Gastroenterol. 116 (1999) 1107-1114.

[22] Malik A.C., Reinbold G.W., Vedamuthu E.R., An evaluation of the taxonomy of Propionibacterium, Can. J. Microbiol. 14 (1968) 1185-1191.

[23] Mao Y., Nobaek S., Kasravi B., Adawi D., Stenram U., Molin G., Jeppsson B., The effects of Lactobacillus strains and oat fiber on methotrexate-induced enterocolitis in rats, Gastroenterol. 111 (1996) 334-344.

[24] Matsuki T., Watanabe K., Fujimoto J., Kado Y., Takada T., Matsumoto K., Tanaka R., Quantitative PCR with 16S rRNA-gene-targeted species-specific primers for analysis of human intestinal bifidobacteria, Appl. Environ. Microbiol. 70 (2004) 167-173.

[25] McCafferty D.M., Mudgett J.S., Swain M.G., Kubes P., Inducible nitric oxide synthase plays a critical role in resolving intestinal inflammation, Gastroenterol. 112 (1997) 1022-1027.

[26] Menchen L.A., Colon A.L., Moro M.A., Leza J.C., Lizasoain I., Menchen P., Alvarez E., Lorenzo P., N-(3-(aminomethyl)benzyl)acetamidine, an inducible nitric oxide synthase inhibitor, decreases colonic inflammation induced by trinitrobenzene sulphonic acid in rats, Life Sci. 69 (2001) 479-491.

[27] Morata de Ambrosini V., Gonzalez S. Perdigon G., de Ruiz Holgado A.P., Oliver G., Immunostimulating activity of cell walls from lactic acid bacteria and related species, Food Agric. Immunol. 10 (1998) 183-191.

[28] Moreau N.M., Champ M.M., Goupry S.M., Le Bizec B.J., Krempf M., Nguyen P.G., Dumon H.J., Martin L.J., Resistant starch modulates in vivo colonic butyrate uptake and its oxidation in rats with dextran sulfate sodium-induced colitis, J. Nutr. 134 (2004) 493-500.

[29] Mori H., Sato Y., Taketomo N., Kamiyama T., Yoshiyama Y., Meguro S., Sato H., Kaneko T., Isolation and structural identification of bifidogenic growth stimulator produced by Propionibacterium freudenreichii, J. Dairy Sci. 80 (1997) 1959-1964.

[30] Morris G.P., Beck P.L., Herridge M.S., Depew W.T., Szewczuk M.R., Wallace J.L., Hapten-induced model of chronic inflammation and ulceration in the rat colon, Gastroenterol. 96 (1989) 795-803. 
[31] Osman N., Adawi D., Ahrne S., Jeppsson B., Molin G., Modulation of the effect of dextran sulfate sodium-induced acute colitis by the administration of different probiotic strains of Lactobacillus and Bifidobacterium, Dig. Dis. Sci. 49 (2004) 320-327.

[32] Ouwehand A.C., Suomalainen T., Tölkkö S., Salminen S., In vitro adhesion of propionic acid bacteria to human intestinal mucus, Lait 82 (2002) 123-130.

[33] Parham N.J., Gibson G.R., Microbes involved in dissimilatory nitrate reduction in the human large intestine, FEMS Microbiol. Ecol. 31 (2000) 21-28.

[34] Pavlick K.P., Laroux F.S., Fuseler J., Wolf R.E., Gray L., Hoffman J., Grisham M.B. Role of reactive metabolites of oxygen and nitrogen in inflammatory bowel disease, Free Radic. Biol. Med. 33 (2002) 311-322.

[35] Perez Chaia A., Nader de Macias M.E., Oliver G., Propionibacteria in the gut: effect on some metabolic activities of the host, Lait 75 (1995) 435-445.

[36] Perez Chaia A., Zarate G., Oliver G., The probiotic properties of propionibacteria, Lait 79 (1999) 175-185.

[37] Perner A., Rask-Madsen J., The potential role of nitric oxide in chronic inflammatory bowel disorders, Aliment Pharmacol. Ther. 13 (1999) 135-144.

[38] Rachmilewitz D., Stamler J.S., Bachwich D., Karmeli F., Ackerman Z., Podolsky D.K., Enhanced colonic nitric oxide generation and nitric oxide synthase activity in ulcerative colitis and Crohn's disease, Gut 36 (1995) 718-723.

[39] Rigaud D., Angel L.A., Cerf M., Carduner M.J., Melchior J.C., Sautier C., Rene E., Apfelbaum M., Mignon M., Mechanisms of decreased food intake during weight loss in adult Crohn's disease patients without obvious malabsorption, Amer. J. Clin. Nutr. 60 (1994) 775-781.

[40] Saito Y., Sakamoto M., Takizawa S., Benno Y., Monitoring the cell number and viability of Lactobacillus helveticus GCL1001 in human feces by PCR methods, FEMS Microbiol. Lett. 231 (2004) 125-130.

[41] Sartor R.B., Therapeutic manipulation of the enteric microflora in inflammatory bowel diseases: antibiotics, probiotics, and prebiotics, Gastroenterol. 126 (2004) 1620-1633.

[42] Schiffrin E.J., Brassart D., Servin A.L., Rochat F., Donnet-Hughes A., Immune modulation of blood leukocytes in humans by lactic acid bacteria: criteria for strain selection, Amer. J. Clin. Nutr. 66 (1997) 515S-520S.

[43] Vardareli E., Dundar E., Angin K., Saricam T., Inal M., Effects of intrarectal and intraperitoneal N(G)-nitro-L-arginine methyl ester treatment in 2,4,6-trinitrobenzenesulfonic acid induced colitis in rats, Exp. Toxicol. Pathol. 55 (2003) 271-276.

[44] Wallace J.L., Vergnolle N., Muscara M.N. Asfaha S., Chapman K., McKnight W., Del Soldato P., Morelli A., Fiorucci S., Enhanced anti-inflammatory effects of a nitric oxidereleasing derivative of mesalamine in rats, Gastroenterol. 117 (1999) 557-566.

[45] Wolf G., Arendt E.K., Pfähler U., Hammes WP., Heme-dependent and heme-independent nitrite reduction by lactic acid bacteria results in different $\mathrm{N}$-containing products, Int. J. Food Microbiol. 10 (1990) 323-330.

[46] Xu J., Verstraete W., Evaluation of nitric oxide production by lactobacilli, Appl. Microbiol. Biotechnol. 56 (2001) 504-507.

[47] Yoshida Y., Iwai A., Itoh K., Tanaka M., Kato S., Hokari R., Miyahara T., Koyama H., Miura S., Kobayashi M., Role of inducible nitric oxide synthase in dextran sulphate sodium-induced colitis, Aliment Pharmacol. Ther. 14 (2000) 26-32.

[48] Zarate G., Morata de Ambrosini V.I., Perez Chaia A., Gonzalez S.N., Adhesion of dairy propionibacteria to intestinal epithelial tissue in vitro and in vivo, J. Food Prot. 65 (2002) 534-539.

[49] Zumft W.G., Cell biology and molecular basis of denitrification, Microbiol. Mol. Biol. Rev. 61 (1997) 533-616. 